\title{
Skin autofluorescence predicts incident type 2 diabetes, cardiovascular disease and mortality in the general population
}

\author{
Robert P. van Waateringe ${ }^{1} \cdot$ Bernardina T. Fokkens ${ }^{2} \cdot$ Sandra N. Slagter $^{1} \cdot$ Melanie M. van der Klauw $^{1}$. \\ Jana V. van Vliet-Ostaptchouk ${ }^{1} \cdot$ Reindert Graaff $^{1} \cdot$ Andrew D. Paterson $^{3} \cdot$ Andries J. Smit $^{2} \cdot$ Helen L. Lutgers $^{4}$. \\ Bruce H. R. Wolffenbuttel ${ }^{1}$
}

Received: 1 May 2018 / Accepted: 4 October 2018 / Published online: 21 November 2018

(C) The Author(s) 2018

\begin{abstract}
Aims/hypothesis Earlier studies have shown that skin autofluorescence measured with an AGE reader estimates the accumulation of AGEs in the skin, which increases with ageing and is associated with the metabolic syndrome and type 2 diabetes. In the present study, we examined whether the measurement of skin autofluorescence can predict 4 year risk of incident type 2 diabetes, cardiovascular disease (CVD) and mortality in the general population.

Methods For this prospective analysis, we included 72,880 participants of the Dutch Lifelines Cohort Study, who underwent baseline investigations between 2007 and 2013, had validated baseline skin autofluorescence values available and were not known to have diabetes or CVD. Individuals were diagnosed with incident type 2 diabetes by self-report or by a fasting blood glucose $\geq 7.0 \mathrm{mmol} / 1$ or $\mathrm{HbA}_{1 \mathrm{c}} \geq 48 \mathrm{mmol} / \mathrm{mol}(\geq 6.5 \%)$ at follow-up. Participants were diagnosed as having incident CVD (myocardial infarction, coronary interventions, cerebrovascular accident, transient ischaemic attack, intermittent claudication or vascular surgery) by self-report. Mortality was ascertained using the Municipal Personal Records Database.

Results After a median follow-up of 4 years (range $0.5-10$ years), 1056 participants (1.4\%) had developed type 2 diabetes, 1258 individuals (1.7\%) were diagnosed with CVD, while 928 (1.3\%) had died. Baseline skin autofluorescence was elevated in participants with incident type 2 diabetes and/or CVD and in those who had died (all $p<0.001$ ), compared with individuals who survived and remained free of the two diseases. Skin autofluorescence predicted the development of type 2 diabetes, CVD and mortality, independent of several traditional risk factors, such as the metabolic syndrome, glucose and $\mathrm{HbA}_{1 \mathrm{c}}$.

Conclusions/interpretation The non-invasive skin autofluorescence measurement is of clinical value for screening for future risk of type 2 diabetes, CVD and mortality, independent of glycaemic measures and the metabolic syndrome.
\end{abstract}

Keywords Ageing $\cdot$ Cardiovascular $\cdot$ Diabetes $\cdot$ Mortality $\cdot$ Prediction $\cdot$ Skin autofluorescence

Electronic supplementary material The online version of this article (https://doi.org/10.1007/s00125-018-4769-x) contains peer-reviewed but unedited supplementary material, which is available to authorised users.

Bruce H. R. Wolffenbuttel

bwo@umcg.nl

1 Department of Endocrinology, University of Groningen, University Medical Center Groningen, Hanzeplein 1, P.O. Box 30001, HPC AA31 9700 RB Groningen, the Netherlands

2 Department of Internal Medicine, University of Groningen, University Medical Center Groningen, Groningen, the Netherlands

3 Program in Genetics and Genome Biology, Hospital for Sick Children, Toronto, ON, Canada

4 Department of Internal Medicine, Medical Center Leeuwarden, Leeuwarden, the Netherlands

$\begin{array}{ll}\text { Abbreviations } \\ \text { AU } & \text { Arbitrary units } \\ \text { CVD } & \text { Cardiovascular disease } \\ \text { eGFR } & \text { Estimated GFR } \\ \text { IQR } & \text { Interquartile range } \\ \text { SAF } & \text { Skin autofluorescence }\end{array}$

\section{Introduction}

The worldwide prevalence of type 2 diabetes is increasing rapidly; it is predicted to be close to 650 million in 2040 . Cardiovascular complications are the main drivers of increased morbidity and premature mortality in diabetes [1-3]. Several risk factors, such as degree of obesity, fasting blood glucose level and presence of the metabolic syndrome, predict 


\section{Research in context}

\section{What is already known about this subject?}

- Skin autofluorescence, measured with an AGE reader, estimates AGE accumulation in the skin

- Skin autofluorescence increases with ageing, and is associated with the metabolic syndrome and type 2 diabetes

- Skin autofluorescence predicts the development of diabetes-related complications

What is the key question?

- Can the measurement of skin autofluorescence predict 4 year risk of incident type 2 diabetes, cardiovascular disease and mortality in the general population?

What are the new findings?

- Baseline skin autofluorescence was elevated in participants with incident type 2 diabetes and/or cardiovascular disease and in those who had died (all $p<0.001$ ), compared with individuals who survived and remained free of the two diseases

- Skin autofluorescence predicted the development of type 2 diabetes, cardiovascular disease and mortality, independent of several traditional risk factors, such as the metabolic syndrome, glucose and $\mathrm{HbA}_{1 c}$

How might this impact on clinical practice in the foreseeable future?

- Non-invasive measurement of skin autofluorescence can be used in the general population to estimate the risk of type 2 diabetes, cardiovascular disease and mortality

the development of type 2 diabetes and cardiovascular disease (CVD), and several risk scores have been developed to increase the reliability of disease prediction [4-7].

In the last two decades, the role of AGEs in ageing and the pathophysiology of diabetes-related complications has been studied extensively. AGEs are formed in a multistep process by glycation and oxidation of free amino groups of proteins, lipids and nucleic acids. In addition to the classic Maillard reaction, AGEs are formed through the reaction of amino groups with $\alpha$-dicarbonyls, such as 3-deoxyglucosone, methylglyoxal and glyoxal [8-10]. AGEs may form cross-links between tissue proteins in the vascular wall, causing increased vascular stiffness and elevated BP $[11,12]$. Moreover, binding of circulating AGE to its receptor (receptor for AGE [RAGE]) and uptake into the vessel wall may accelerate the progression of atherosclerosis $[13,14]$. AGEs may also induce beta cell damage by increasing inflammation and oxidative stress and thereby contribute to worsening of hyperglycaemia $[15,16]$.

The accumulation of AGEs can be assessed noninvasively by measuring skin autofluorescence (SAF) [17]. This method is based on the fluorescent properties of certain AGEs accumulated in dermal tissue. Validation studies have shown that SAF is strongly related to AGE levels in skin biopsies [18]. SAF increases with ageing, and is elevated in people with type 2 diabetes compared with age-matched control individuals $[19,20]$. We have recently demonstrated that SAF is already elevated in people without diabetes but with the metabolic syndrome and is associated with its individual components [21]. SAF is strongly associated with long-term cardiovascular complications and mortality in type 2 diabetes [19, 22-24].

Long-term prospective studies on the value of SAF to predict development of type 2 diabetes, CVD and mortality in the general population are lacking. However, SAF was associated with increased mortality and cardiovascular events in specific groups and, for example, predicted amputations in individuals with peripheral artery disease $[25,26]$.

Because of the promise of SAF as a valuable biomarker, the goal of this study was to assess whether SAF was able to predict the development of type 2 diabetes, CVD and mortality in the general population. For this, we performed an extensive prospective follow-up study of individuals participating in the Dutch Lifelines Cohort Study.

\section{Methods}

Participants Participants from the Lifelines Cohort Study, a large population-based study in the northern region of the Netherlands (electronic supplementary material [ESM] Methods), were included [27]. At baseline, both physical examination and extensive questionnaire data were collected [28]. All individuals provided written informed consent before participating in the study, which was approved by the Medical Ethics Review Committee of the University Medical Center Groningen. 
For the present study, we evaluated 82,904 participants of Western European descent between 18 and 90 years of age, who underwent baseline investigations between 2007 and 2013, and for whom validated SAF measurement was available at baseline and prospective follow-up was performed between January 2014 and January 2018. There were no relevant differences in sex distribution, age and glycaemic variables between those with and without SAF measurements. We excluded participants who, at baseline, had clinical CVD $(n=$ $1861)$ and/or type 1 diabetes $(n=177)$ and/or type 2 diabetes $(n=2557)$ or reported a history of gestational diabetes $(n=$ $134)$ or MODY $(n=4)$. Furthermore, individuals with new type 1 diabetes $(n=12)$ and a new history of gestational diabetes $(n=55)$ at follow-up were excluded, as well as those without documented follow-up $(n=5530)$. This resulted in 72,880 individuals available for analyses (ESM Fig. 1). Of these, 59,583 participated in the second screening, filled in the follow-up questionnaires and underwent follow-up examination with detailed BP measurement and laboratory examinations (ESM Methods), while only interim questionnaire data were available for 13,297 individuals. Median follow-up was 4 years, with a range of $0.5-10$ years, for a total of 274,629 participant-years (ESM Fig. 2). Median follow-up for the 59,583 participants who had completed the second screening visit and measurements was 4.1 years. Follow-up measurements of fasting blood glucose and $\mathrm{HbA}_{1 \mathrm{c}}$ were available for 55,759 (76.5\%) and 56,086 (77\%) participants, respectively.

Clinical examination At both baseline and follow-up examination, participants completed a self-administered questionnaire on medical history, past and current diseases, and health behaviour. Medication use was verified at baseline by a certified research assistant and scored using the Anatomical Therapeutic Chemical (ATC) Classification System. Information regarding smoking behaviour (never, former and current smoking) and quantity smoked, as well as coffee consumption (cups/day), was collected from the questionnaires [29]. Weight was measured to the nearest $0.1 \mathrm{~kg}$ and height and waist circumference to the nearest $0.5 \mathrm{~cm}$, with participants wearing light clothing and no shoes. BMI was calculated as $\mathrm{kg} / \mathrm{m}^{2}$. Systolic and diastolic BP and heart rate were measured every minute for $10 \mathrm{~min}$ in the supine position using an automated Dinamap monitor (GE Healthcare, Freiburg, Germany). The average of the last three readings was recorded for each BP variable and heart rate.

Skin autofluorescence SAF was measured non-invasively using an AGE reader (Diagnoptics Technologies, Groningen, the Netherlands), as described previously [17, 20]. The AGE reader illuminates a skin surface of approximately $4 \mathrm{~cm}^{2}$, guarded against surrounding light, with an excitation light source with wavelength between 300 and
$420 \mathrm{~nm}$ (peak intensity at $\sim 370 \mathrm{~nm}$ ). Emission light and reflected excitation light from the skin are measured with an internal spectrometer in the range 300-600 nm. SAF was based on the ratio of the average emitted light intensity per $\mathrm{nm}$ in the range 420-600 $\mathrm{nm}$ and the average reflected light intensity per $\mathrm{nm}$ in the range $300-420 \mathrm{~nm}$, multiplied by 100 , and is expressed in arbitrary units (AU), taking skin colour into account [30]. Previous studies have shown an error rate of $5 \%$ when repeated SAF measurements were taken over a single day in control participants and individuals with diabetes [17]. More details about the number of machines and validation of measurements are given in the ESM Methods. Ageadjusted SAF levels ( $z$ scores) were calculated separately for men and women, based on the total population.

Biochemical measurements Blood samples were taken in the fasting state between 08:00 and 10:00 hours and transported to the laboratory facility at room temperature or $4^{\circ} \mathrm{C}$, depending on the sample requirements. On the same day, $\mathrm{HbA}_{1 \mathrm{c}}$ (EDTAanticoagulated) was analysed using an NGSP-certified turbidimetric inhibition immunoassay on a Cobas Integra 800 CTS analyser (Roche Diagnostics Nederland, Almere, the Netherlands). Serum creatinine was measured on a Roche Modular P chemistry analyser (Roche, Basel, Switzerland) and renal function was calculated as estimated (e)GFR with the formula developed by the Chronic Kidney Disease Epidemiology Collaboration (CKD-EPI) [31]. Total cholesterol and HDL-cholesterol were measured using an enzymatic colorimetric method, triacylglycerol using a colorimetric UV method, and LDL-cholesterol using an enzymatic method, on a Roche Modular P chemistry analyser (Roche). Fasting blood glucose was measured using a hexokinase method.

Calculations, definitions and statistical analyses Diagnosis of the metabolic syndrome was established if a participant at baseline satisfied at least three out of five criteria according to the modified guidelines of the National Cholesterol Education Programs Adults Treatment Panel III (NCEP ATPIII criteria): (1) systolic BP $\geq 130 \mathrm{mmHg}$ and/or diastolic $\mathrm{BP} \geq 85 \mathrm{mmHg}$ and/or use of antihypertensive medication; (2) HDL-cholesterol levels $<1.03 \mathrm{mmol} / 1$ in men and $<1.30 \mathrm{mmol} / \mathrm{l}$ in women and/or use of lipid-lowering medication influencing HDL-cholesterol levels; (3) triacylglycerol levels $\geq 1.70 \mathrm{mmol} / 1$ and/or use of triacylglycerol-lowering medication; (4) waist circumference $\geq 102 \mathrm{~cm}$ in men and $\geq 88 \mathrm{~cm}$ in women; (5) fasting glucose level $\geq 5.6 \mathrm{mmol} / 1$ and/or use of blood glucose-lowering medication and/or diagnosis of type 2 diabetes [32]. Incident type 2 diabetes was based on either self-report or fasting blood glucose $\geq 7.0 \mathrm{mmol} / 1$ and/or $\mathrm{HbA}_{1 \mathrm{c}} \geq 48 \mathrm{mmol} / \mathrm{mol}(\geq 6.5 \%)$ at follow-up evaluation. Incident CVD was defined as present when participants reported myocardial infarction, percutaneous transluminal coronary angioplasty (PTCA), stent 
positioning, coronary artery bypass grafting $(\mathrm{CABG})$, transient ischaemic attack (TIA), cerebrovascular accident (CVA), intermittent claudication or peripheral artery vascular surgery. Vital status was ascertained with the Municipal Personal Records Database (GBA). Data on cause of death were not available. The incidence of type 2 diabetes, CVD and mortality was calculated separately and as a composite outcome for all age-decade groups (18-29, 30-39, 40-49, $50-59,60-69,70-79, \geq 80$ years)..

All analyses were conducted using PASW Statistics (Version 22, IBM, Armonk, NY, USA). Data are presented as mean $\pm \mathrm{SD}$, or median and interquartile range (IQR) when not normally distributed. Means were compared between groups with ANOVA. When variables were not normally distributed, medians were compared using the non-parametric Mann-Whitney $U$ test. The $\chi^{2}$ test was used to analyse categorical variables. Uni- and multivariate logistic regression analyses were performed to examine the association between SAF and the composite outcome of incident type 2 diabetes, CVD and mortality, as well as these outcomes separately, while adjusting for relevant clinical, biochemical and lifestyle risk factors. In our models, we adjusted for the most important determinants of SAF, i.e. age (model 1, used as a basic model), additionally adjusted for presence of the metabolic syndrome (model 2), glycaemic variables (model $3 \mathrm{a} / \mathrm{b}$ ), confounding non-biochemical factors (model 4) and all relevant factors (model 5). As age is an important factor influencing not only SAF measurements, but also the absolute incidence of events, we calculated the association between SAF and outcome according to four clinically relevant age groups, considered as low, intermediate, high and very high risk: $\leq 35$ years; $36-$ 50 years; $\geq 51$ years; and $\geq 61$ years. Values of $p<0.05$ were considered statistically significant.

\section{Results}

Incidence of type 2 diabetes, CVD and mortality The incidence of all outcomes is shown in Table 1. An individual may have had more than one outcome. After a median follow-up of 4 years, 1056 individuals had developed type 2 diabetes $(1.4 \%)$. Of those, 525 reported that they had been diagnosed with type 2 diabetes between the baseline visit and the follow-up measurement, while in those not reporting a diagnosis of diabetes, fasting blood glucose $\geq 7.0 \mathrm{mmol} / 1$ was observed in 408 participants, elevated $\mathrm{HbA}_{1 \mathrm{c}}$ $\geq 48 \mathrm{mmol} / \mathrm{mol}(\geq 6.5 \%)$ in 268 , and either elevated blood glucose or $\mathrm{HbA}_{1 \mathrm{c}}$ in 531 participants.

Individuals with incident type 2 diabetes were significantly older at baseline than participants who did not develop type 2 diabetes $(51.8 \pm 11.4$ years vs $43.7 \pm 12.0$ years, $p<0.001)$, and had a higher baseline BMI, fasting glucose and $\mathrm{HbA}_{1 \mathrm{c}}$ (all $p<0.001$, Table 2). Moreover, the prevalence of the
Table 1 Clinical endpoints as defined in the study

\begin{tabular}{|c|c|}
\hline Clinical endpoint & $n$ \\
\hline No type 2 diabetes, CVD or death & 69,749 \\
\hline Incident type 2 diabetes only & 977 \\
\hline Incident CVD only & 1171 \\
\hline Death $^{\mathrm{a}}$ & 874 \\
\hline Incident type 2 diabetes and CVD & 55 \\
\hline Type 2 diabetes and death & 22 \\
\hline CVD and death & 30 \\
\hline Type 2 diabetes, CVD and death & 2 \\
\hline
\end{tabular}

72,880 participants in total

${ }^{\mathrm{a}}$ Without/before ascertainment of diabetes or CVD status

metabolic syndrome was also higher. As expected, the incidence of type 2 diabetes increased with age, and was between $3.3 \%$ and $4.1 \%$ in the three highest age decades (Fig. 1a). Mean baseline SAF $z$ score was $0.16 \pm 0.95$ in participants with incident type 2 diabetes and $-0.01 \pm 0.81$ in individuals who remained healthy $(p<0.001$, Fig. 2$)$.

In the same population, 1258 individuals $(1.7 \%)$ had developed CVD at follow-up (Table 1). Participants with incident CVD were significantly older at baseline, had a higher waist circumference, higher systolic BP and diastolic BP, higher lipid levels and a lower eGFR $(p<0.001$, Table 2$)$. As expected, incidence of CVD increased with age, and was between $4.5 \%$ and $11.6 \%$ in the three highest age decades (Fig. 1b). Mean baseline SAF $z$ score was $0.16 \pm 0.96$ among the population with incident CVD vs $-0.01 \pm 0.81$ in participants who did not develop CVD or type 2 diabetes $(p<0.001$, Fig. 2). In total, 55 individuals developed both type 2 diabetes and CVD, and these had the highest baseline SAF $z$ scores ( $p<0.001$ vs no disease, $p=0.004$ vs type 2 diabetes [in women only], Fig. 2).

Death was reported in 928 individuals (1.3\%). As expected, mortality increased with age (Fig. 1c). Participants who died were older at baseline, had higher BP, were more likely to have impaired renal function/low eGFR and were more frequently current smokers. They also had higher SAF levels, even when corrected for age, than individuals who developed type 2 diabetes or CVD or remained without these disorders (Table 2).

ESM Table 1 details the mean age and SAF levels according to each age group. In almost all age groups, SAF was significantly higher $(p<0.0001)$ in those participants who developed an event (the composite outcome of incident type 2 diabetes, CVD and mortality) compared with those who remained free from these events.

Association and prediction Table 3 shows the results of the univariate and multivariate associations between SAF and clinical, biochemical and lifestyle factors and the composite 
Table 2 Clinical characteristics of the study population at baseline in relation to outcome status

\begin{tabular}{|c|c|c|c|c|}
\hline \multirow[t]{2}{*}{ Characteristic } & \multicolumn{4}{|l|}{ Incident } \\
\hline & None & $\mathrm{T} 2 \mathrm{D}$ & CVD & Death \\
\hline Sex ( $n$; male/female) & $28,021 / 41728$ & $524 / 532$ & $637 / 621$ & $489 / 439$ \\
\hline Men $(\%)$ & 40.2 & 49.6 & 50.6 & 52.7 \\
\hline Age (years) & $43.7 \pm 12.0$ & $51.8 \pm 11.4$ & $54.2 \pm 12.0$ & $58.0 \pm 12.7$ \\
\hline BMI $\left(\mathrm{kg} / \mathrm{m}^{2}\right)$ & $25.8 \pm 4.1$ & $29.7 \pm 5.0$ & $27.1 \pm 4.0$ & $26.8 \pm 4.3$ \\
\hline Waist (cm) & $90 \pm 12$ & $101 \pm 13$ & $95 \pm 12$ & $95 \pm 13$ \\
\hline Systolic BP (mmHg) & $125 \pm 15$ & $134 \pm 16$ & $133 \pm 17$ & $134 \pm 18$ \\
\hline Diastolic BP (mmHg) & $74 \pm 9$ & $78 \pm 10$ & $77 \pm 10$ & $77 \pm 10$ \\
\hline Heart rate (bpm) & $71 \pm 11$ & $73 \pm 11$ & $71 \pm 11$ & $71 \pm 12$ \\
\hline Creatinine $(\mu \mathrm{mol} / \mathrm{l})$ & $73 \pm 13$ & $75 \pm 15$ & $76 \pm 14$ & $77 \pm 22$ \\
\hline eGFR (ml/min) & $97 \pm 15$ & $92 \pm 15$ & $90 \pm 15$ & $87 \pm 16$ \\
\hline Total cholesterol (mmol/l) & $5.1 \pm 1.0$ & $5.3 \pm 1.0$ & $5.4 \pm 1.0$ & $5.4 \pm 1.0$ \\
\hline HDL-cholesterol (mmol/l) & $1.49 \pm 0.39$ & $1.29 \pm 0.37$ & $1.43 \pm 0.40$ & $1.46 \pm 0.41$ \\
\hline LDL-cholesterol (mmol/l) & $3.2 \pm 0.9$ & $3.4 \pm 0.9$ & $3.6 \pm 1.0$ & $3.5 \pm 0.9$ \\
\hline \multirow[t]{2}{*}{ Triacylglycerol (mmol/l) } & 0.96 & 1.41 & 1.16 & 1.12 \\
\hline & $(0.70-1.36)$ & $(1.02-2.00)$ & $(0.84-1.63)$ & $(0.84-1.62)$ \\
\hline Glucose (mmol/l) & $4.9 \pm 0.5$ & $5.7 \pm 0.7$ & $5.1 \pm 0.5$ & $5.1 \pm 0.5$ \\
\hline $\mathrm{HbA}_{1 \mathrm{c}}(\mathrm{mmol} / \mathrm{mol})$ & $36 \pm 3$ & $40 \pm 4$ & $38 \pm 3$ & $38 \pm 4$ \\
\hline $\mathrm{HbA}_{1 \mathrm{c}}(\%)$ & $5.5 \pm 0.3$ & $5.9 \pm 0.3$ & $5.7 \pm 0.3$ & $5.7 \pm 0.3$ \\
\hline Current smokers (\%) & 20.4 & 22.3 & 25.8 & 26.9 \\
\hline Former smokers (\%) & 30.8 & 39.4 & 40.6 & 40.4 \\
\hline Metabolic syndrome (\%) & 12.8 & 57.5 & 25.1 & 25.6 \\
\hline Skin autofluorescence (AU) & $1.90 \pm 0.42$ & $2.13 \pm 0.45$ & $2.18 \pm 0.47$ & $2.33 \pm 0.52$ \\
\hline SAF $z$ score & $-0.01 \pm 0.81$ & $0.16 \pm 0.95$ & $0.16 \pm 0.96$ & $0.33 \pm 1.13$ \\
\hline
\end{tabular}

Data are presented as mean $\pm \mathrm{SD}$, median (IQR), number or $\%$

$p<0.001$ vs the group without incident type 2 diabetes, CVD or death in all analyses (except heart rate) by ANOVA

T2DM, type 2 diabetes outcome of incident type 2 diabetes, CVD and mortality. Univariate analyses showed that SAF was strongly associated with these outcomes (OR 3.84, 95\% CI 3.57, 4.11, $p=1.5 \times$ $\left.10^{-307}\right)$. This association remained significant after adjusting for age (model 1), age and the metabolic syndrome (model 2) and also after adjusting for age, fasting glucose (OR 1.79, $95 \%$ CI $1.64,1.96, p=1.1 \times 10^{-37}$ ) or $\mathrm{HbA}_{1 \mathrm{c}}(\mathrm{OR} 1.78$, $95 \%$ CI $\left.1.63,1.95, p=6.6 \times 10^{-38}\right)$. Additional regression models revealed that the association also remained significant when adjusted for sex, waist circumference and current smoking (model 4), as well as all for other variables including systolic BP, plasma lipids, eGFR and coffee consumption (model 5, OR 1.54, 95\% CI 1.40, 1.70, $p=3.9 \times 10^{-18}$ ). In the composite multivariate model 5 , age, glucose, waist circumference, current smoking, systolic blood pressure and triacylglycerol were most strongly associated with the composite outcome (Table 3 ).

Additionally, we assessed the relationship between SAF and the three individual outcomes separately (Table 4). In a univariate model, SAF was most strongly associated with death (OR 5.10, 95\% CI 4.56, 5.70, $\left.p=4.1 \times 10^{-181}\right)$. This association remained highly significant after adjusting for age (model 1), presence of the metabolic syndrome (model 2 ), glycaemic variables (model $3 \mathrm{a} / \mathrm{b}$ ) and other possible confounding, non-biochemical factors (model 4). Model 5 showed that male sex, waist, systolic BP, cholesterol and current smoking, in addition to SAF and age, were independently associated with mortality. Similarly, univariate regression analyses revealed SAF to be strongly associated with both incident type 2 diabetes and incident CVD separately (Table 4). In addition to SAF and age, the strongest predictors of incident type 2 diabetes were fasting glucose, $\mathrm{HbA}_{1 \mathrm{c}}$, triacylglycerol, BMI, waist circumference, BP and the presence of the metabolic syndrome. The strongest univariate predictors for CVD were - again in addition to SAF and age - waist circumference, $\mathrm{BMI}$, glucose, $\mathrm{Hb}_{1 \mathrm{c}}$, $\mathrm{BP}, \mathrm{eGFR}$ and presence of the metabolic syndrome. SAF remained significantly associated with type 2 diabetes and incident CVD in the first four multivariate models. Also in these multivariate models, the presence of the metabolic syndrome, fasting glucose and 

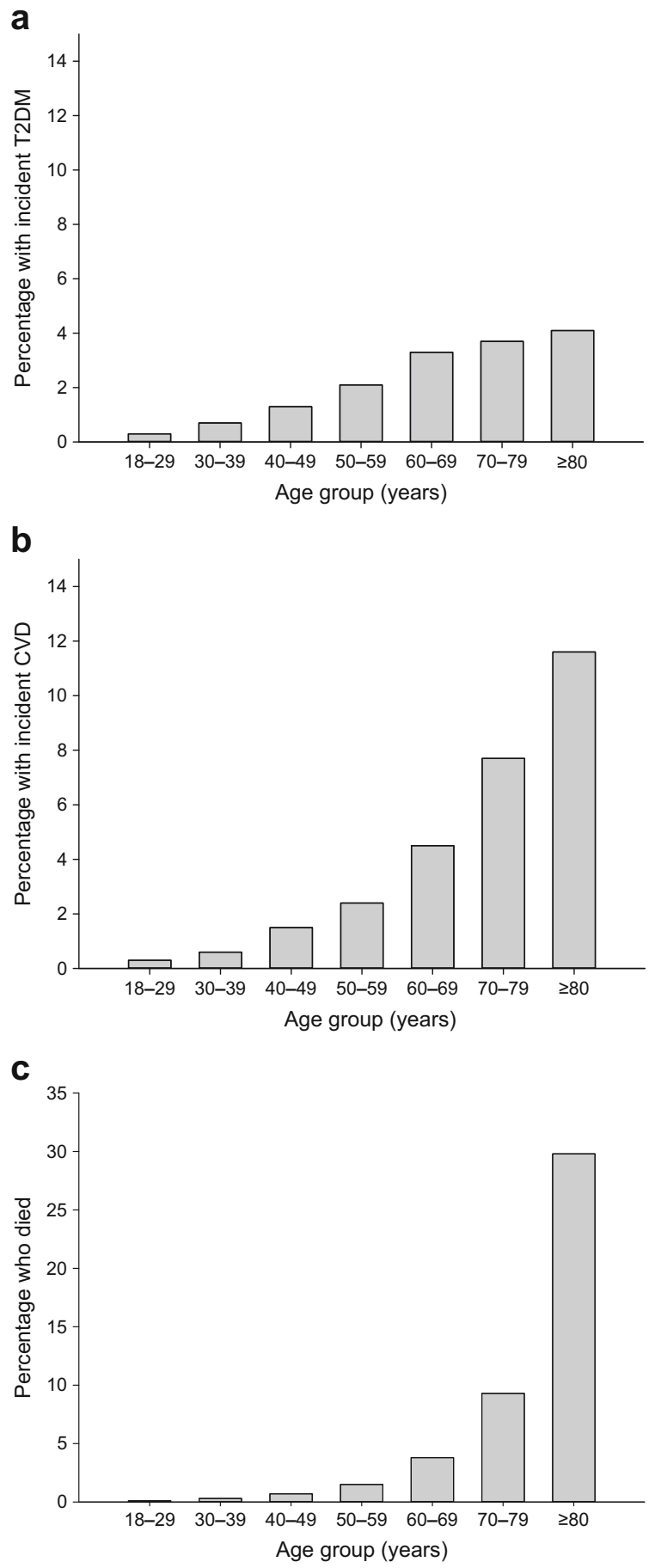

Fig. 1 Proportion of participants per age decade (a) with incident type 2 diabetes, (b) with incident CVD and (c) who died. T2DM, type 2 diabetes

$\mathrm{HbA}_{1 \mathrm{c}}$ levels was strongly associated with incident type 2 diabetes and moderately associated with incident CVD. In the final model (model 5), SAF still was significant, and age, glucose, waist circumference, male sex and triacylglycerol were the strongest factors associated with incident type 2 diabetes, and age, waist circumference, systolic BP and current smoking were the strongest factors associated with incident CVD.

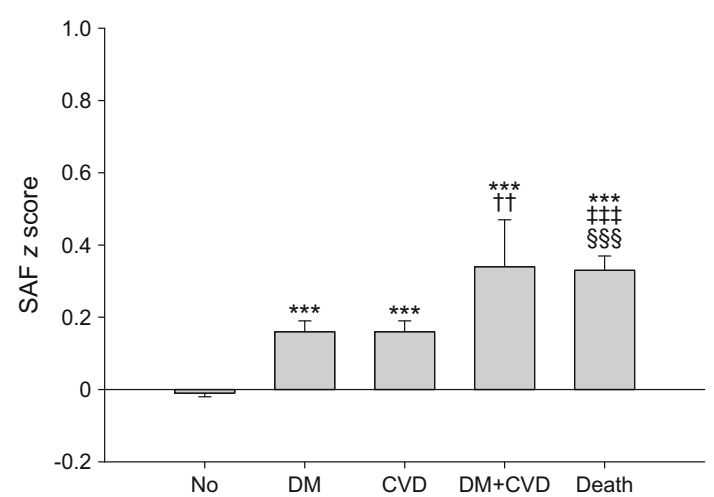

Fig. 2 Baseline SAF $z$ scores according to diabetes, CVD and vital status at 4 years of follow-up. Data are presented as means \pm standard error. No type 2 diabetes/CVD (No), $n=69,749$; type 2 diabetes (DM), $n=977$; CVD, $n=1171 ; \mathrm{DM}+\mathrm{CVD}, n=55$; death, $n=928$. $* * * p<0.001$ vs no type 2 diabetes/CVD group; ${ }^{\dagger \dagger} p<0.005$ (women only) vs DM group; $\pitchfork p<0.001$ vs DM group; ${ }^{\$ \& \$} p<0.001$ vs CVD group

As the time of death of all participants was recorded, we were able to show the effect of SAF on time from baseline to death. As can be seen in ESM Fig. 3, the highest SAF $z$ score tertile was associated with an almost twofold increased risk of mortality compared with the other tertiles.

Finally, as age is an important factor influencing SAF measurements, but also the absolute incidence of outcome events (Fig. 1), we calculated the association between age-corrected SAF score and outcome according to four clinically relevant age groups (Table 5). SAF score was significantly associated with the composite outcome and with mortality in all age groups. For incident type 2 diabetes, in participants aged $\leq 35$ years and those between 51 and 60 years SAF was not significant. For CVD, there was no significant predictive value in the lowest age group probably because of the low number of events.

\section{Discussion}

This prospective study within the general population demonstrates that SAF is significantly associated with new-onset type 2 diabetes, CVD and mortality during a median followup of 4 years. SAF predicted these combined outcomes independently of several conventional risk factors, including age, sex, waist circumference, the metabolic syndrome, smoking status, fasting glucose and/or $\mathrm{HbA}_{1 \mathrm{c}}$.

Both fasting glucose and $\mathrm{HbA}_{1 \mathrm{c}}$ were used to define type 2 diabetes at follow-up, which may have caused overestimation of their predictive values. SAF also significantly predicted mortality alone, even after correction for all relevant risk factors, such as age, sex, waist circumference and smoking. Finally, SAF was most strongly predictive in participants aged 36 and above, probably because of the low incidence of events in the lowest age group (age $\leq 35$ years, Table 5 ). 
Table 3 Univariate and multivariate logistic regression analyses for the composite primary outcome (incident type 2 diabetes, CVD or death) at a median of 4 years' follow-up

\begin{tabular}{|c|c|c|c|c|}
\hline Analysis & $n$ & OR & $95 \% \mathrm{CI}$ & $p$ value \\
\hline \multicolumn{5}{|l|}{ Univariate } \\
\hline SAF (AU) & 72,880 & 3.84 & $3.57,4.11$ & $1.5 \times 10^{-307}$ \\
\hline Age (years) & 72,880 & 1.07 & $1.07,1.08$ & $<1.0 \times 10^{-350}$ \\
\hline Male sex (y/n) & 72,880 & 1.53 & $1.42,1.64$ & $3.9 \times 10^{-31}$ \\
\hline BMI $\left(\mathrm{kg} / \mathrm{m}^{2}\right)$ & 72,866 & 1.10 & $1.09,1.10$ & $2.3 \times 10^{-141}$ \\
\hline Waist circumference $(\mathrm{cm})$ & 72,866 & 1.05 & $1.04,1.05$ & $3.0 \times 10^{-227}$ \\
\hline Glucose $(\mathrm{mmol} / \mathrm{l})$ & 72,223 & 4.02 & $3.77,4.29$ & $<1.0 \times 10^{-350}$ \\
\hline $\mathrm{HbA}_{1 \mathrm{c}}(\mathrm{mmol} / \mathrm{mol})$ & 72,254 & 1.26 & $1.24,1.27$ & $<1.0 \times 10^{-350}$ \\
\hline SBP (mmHg) & 72,853 & 1.03 & $1.03,1.04$ & $1.0 \times 10^{-199}$ \\
\hline DBP (mmHg) & 72,853 & 1.04 & $1.04,1.04$ & $1.5 \times 10^{-100}$ \\
\hline Heart rate $(\mathrm{b} / \mathrm{min})$ & 72,853 & 1.00 & $1.00,1.01$ & 0.021 \\
\hline Cholesterol (mmol/l) & 72,446 & 1.33 & $1.29,1.38$ & $5.8 \times 10^{-60}$ \\
\hline Triacylglycerol (mmol/l) & 72,446 & 1.35 & $1.31,1.40$ & $5.2 \times 10^{-81}$ \\
\hline eGFR (ml/min) & 72,423 & 0.97 & $0.97,0.97$ & $1.0 \times 10^{-155}$ \\
\hline Former smoker (y/n) & 72,127 & 1.51 & $1.40,1.62$ & $9.0 \times 10^{-28}$ \\
\hline Current smoker (y/n) & 72,127 & 1.29 & $1.19,1.40$ & $2.4 \times 10^{-9}$ \\
\hline Coffee consumption (cups/day) & 71,396 & 1.09 & $1.07,1.11$ & $1.3 \times 10^{-27}$ \\
\hline Metabolic syndrome (y/n) & 72,405 & 3.76 & $3.48,4.06$ & $1.5 \times 10^{-250}$ \\
\hline Multivariate model $1^{\mathrm{a}}$ & 72,880 & & & \\
\hline SAF (AU) & & 1.88 & $1.72,2.05$ & $4.4 \times 10^{-46}$ \\
\hline Age (years) & & 1.06 & $1.06,1.06$ & $1.4 \times 10^{-241}$ \\
\hline Multivariate model $2^{\mathrm{b}}$ & 72,405 & & & \\
\hline SAF (AU) & & 1.77 & $1.62,1.93$ & $1.2 \times 10^{-36}$ \\
\hline Age (years) & & 1.06 & $1.05,1.06$ & $1.8 \times 10^{-209}$ \\
\hline Metabolic syndrome (y/n) & & 2.80 & $2.58,3.03$ & $3.1 \times 10^{-142}$ \\
\hline Multivariate model $3 \mathrm{a}^{\mathrm{c}}$ & 72,223 & & & \\
\hline SAF (AU) & & 1.79 & $1.64,1.96$ & $1.1 \times 10^{-37}$ \\
\hline Age (years) & & 1.05 & $1.05,1.05$ & $2.0 \times 10^{-160}$ \\
\hline Glucose (mmol/l) & & 2.90 & $2.71,3.11$ & $1.7 \times 10^{-210}$ \\
\hline Multivariate model $3 \mathrm{~b}^{\mathrm{c}}$ & 72,254 & & & \\
\hline SAF (AU) & & 1.78 & $1.63,1.95$ & $6.6 \times 10^{-38}$ \\
\hline Age (years) & & 1.05 & $1.04,1.05$ & $8.3 \times 10^{-128}$ \\
\hline $\mathrm{HbA}_{1 \mathrm{c}}(\mathrm{mmol} / \mathrm{mol})$ & & 1.16 & $1.14,1.17$ & $1.3 \times 10^{-126}$ \\
\hline Multivariate model $4^{\mathrm{d}}$ & 72,113 & & & \\
\hline SAF (AU) & & 1.55 & $1.41,1.69$ & $9.7 \times 10^{-21}$ \\
\hline Age (years) & & 1.06 & $1.06,1.07$ & $7.7 \times 10^{-229}$ \\
\hline Male sex (y/n) & & 1.10 & $1.02,1.19$ & 0.013 \\
\hline Waist circumference $(\mathrm{cm})$ & & 1.04 & $1.03,1.04$ & $2.5 \times 10^{-104}$ \\
\hline Current smoker $(\mathrm{y} / \mathrm{n})$ & & 1.62 & $1.48,1.78$ & $3.6 \times 10^{-26}$ \\
\hline Multivariate model $5^{\mathrm{e}}$ & 70,612 & & & \\
\hline SAF (AU) & & 1.54 & $1.40,1.70$ & $3.9 \times 10^{-18}$ \\
\hline Age (years) & & 1.06 & $1.05,1.06$ & $1.4 \times 10^{-107}$ \\
\hline Glucose $(\mathrm{mmol} / \mathrm{l})$ & & 2.37 & $2.20,2.55$ & $1.3 \times 10^{-112}$ \\
\hline Current smoker (y/n) & & 1.61 & $1.46,1.77$ & $8.3 \times 10^{-23}$ \\
\hline Waist circumference $(\mathrm{cm})$ & & 1.02 & $1.02,1.02$ & $2.6 \times 10^{-26}$ \\
\hline Male sex (y/n) & & 0.93 & $0.86,1.02$ & 0.108 \\
\hline SBP (mmHg) & & 1.01 & $1.01,1.01$ & $3.6 \times 10^{-10}$ \\
\hline Cholesterol (mmol/l) & & 0.93 & $0.89,0.97$ & 0.001 \\
\hline
\end{tabular}


Table 3 (continued)

\begin{tabular}{lllr}
\hline Analysis & $n$ & OR & $95 \%$ CI \\
\hline Triacylglycerol (mmol/l) & 1.15 & $1.10,1.19$ & 5 value \\
eGFR (ml/min) & 1.00 & $1.00,1.01$ & 0.176 \\
Coffee consumption (cups/day) & 0.99 & $0.97,1.00$ & 0.135 \\
\hline
\end{tabular}

Baseline risk factors were used to predict the median 4 year risk of the composite outcome of type 2 diabetes, CVD and death

$\mathrm{SAF}$, age, glucose, $\mathrm{HbA}_{1 \mathrm{c}}$, waist circumference, systolic BP, cholesterol, triacylglycerol, eGFR and coffee consumption (cups/day) were defined as continuous variables. Male sex, current smoker (vs never smoker) and the metabolic syndrome were defined as categorical variables

${ }^{\text {a }}$ Age-corrected

${ }^{\mathrm{b}}$ Including the metabolic syndrome

${ }^{\mathrm{c}}$ Including glycaemic measures

${ }^{\mathrm{d}}$ Without biochemical markers

${ }^{\mathrm{e}}$ With all variables

DBP, diastolic BP; SBP, systolic BP; y/n, yes/no

The formation and accumulation of AGEs is increased in individuals with diabetes as a result of chronic hyperglycaemia and oxidative stress $[8,33]$. In the present study, SAF levels were already elevated at baseline before diagnosis of type 2 diabetes, compared with people who remained normoglycaemic. Indeed, previously we demonstrated that SAF levels were strongly correlated with presence of the metabolic syndrome, a cluster of risk factors which is associated with increased risk of type 2 diabetes [21]. This association has been confirmed in the present study. However, SAF remained an independent predictor of incident type 2 diabetes, even when adjusted for presence of the metabolic syndrome at baseline. Our analyses also revealed that SAF predicted incident type 2 diabetes when adjusted for fasting glucose and $\mathrm{HbA}_{1 \mathrm{c}}$ levels, and it remained significantly associated even when adjusted for a large number of variables, including glycaemic measures, age, waist circumference, BP, triacylglycerol and eGFR.

Several earlier cross-sectional studies have assessed whether SAF is able to detect undiagnosed type 2 diabetes. Based on various receiver operating characteristic curves, skin fluorescence measured with the Scout DS device had higher sensitivity and specificity compared with fasting plasma glucose and $\mathrm{HbA}_{1 \mathrm{c}}$ in the detection of individuals with undiagnosed abnormal glucose tolerance [34]. However, these analyses were not corrected for important factors such as age, waist circumference, glucose level and smoking status. Another study compared an SAF decision model, based on age percentiles, BMI and family history, with the Finnish Diabetes Risk Score (FINDRISC) questionnaire and conventional risk markers, including fasting plasma glucose and $\mathrm{HbA}_{1 \mathrm{c}}$, for the detection of prevalent impaired glucose tolerance and diabetes [35]. Analyses in a subgroup of individuals, classified a priori as intermediate risk, showed that the SAF-based decision model had a higher sensitivity and specificity compared with fasting plasma glucose alone and the FINDRISC questionnaire, and had a performance equal to $\mathrm{Hb}_{1 \mathrm{c}}$. Finally, our group recently demonstrated in the same Lifelines cohort that measurement of SAF is of additional value to the FINDRISC for detecting current undiagnosed diabetes [36]. Reclassification analysis showed that SAF reclassified 8$15 \%$ of the total population into more accurate risk categories.

In the current study, SAF was also significantly associated with a threefold increased risk of incident CVD. This association remained significant after adjustment for age and sex, as well as the metabolic syndrome, which includes presence of elevated waist circumference, elevated BP, low HDLcholesterol and triacylglycerol, all well-known risk factors for CVD [37, 38]. SAF remained significantly associated even after adjustment for important CVD risk factors such as actual BP levels, total cholesterol and current smoking. It has been demonstrated that tobacco smoking is a strong risk factor for a wide range of CVDs [39, 40]. Tobacco smoke is also an exogenous source of AGEs and increases oxidative stress [41-43]; both active and passive smoking significantly increase SAF $[19,20,44]$. This also suggests that the association between smoking status and risk of CVD may, in part, be explained by increased accumulation of AGEs as a result of tobacco smoking. Also, it should be noted that baseline SAF scores were the highest in individuals who developed both type 2 diabetes and CVD (Fig. 2). Although this is a small subgroup of only 55 participants, it supports the power of SAF for predicting very-high-risk individuals.

The most striking finding was that SAF was associated with a fivefold increased mortality risk in our univariate analysis. This association remained highly significant even after correcting for several confounding factors, including those described in the most extensive fifth model (Table 4). The results in Table 5 showed high ORs that are highly significant for all age groups. As this is the first study that evaluated the effect of SAF in the general non-diabetic population, we have no other study results for comparison. Although several crosssectional studies have demonstrated the association between 
Table 4 Univariate and multivariate logistic regression analyses for the separate primary outcomes (incident type 2 diabetes, CVD or death) at a median of 4 year follow-up

\begin{tabular}{|c|c|c|c|c|c|c|}
\hline \multirow[t]{2}{*}{ Analysis } & \multicolumn{2}{|l|}{ New T2DM } & \multicolumn{2}{|l|}{ New CVD } & \multicolumn{2}{|l|}{ Death } \\
\hline & OR $(95 \% \mathrm{CI})$ & $p$ value & OR $(95 \% \mathrm{CI})$ & $p$ value & OR $(95 \%$ CI) & $p$ value \\
\hline \multicolumn{7}{|l|}{ Univariate analysis $^{\mathrm{a}}$} \\
\hline SAF (AU) & $2.74(2.44,3.07)$ & $1.0 \times 10^{-68}$ & $3.25(2.93,3.60)$ & $2.5 \times 10^{-111}$ & $5.10(4.56,5.70)$ & $4.1 \times 10^{-181}$ \\
\hline Age (years) & $1.05(1.05,1.06)$ & $1.5 \times 10^{-91}$ & $1.07(1.06,1.07)$ & $3.1 \times 10^{-184}$ & $1.10(1.09,1.10)$ & $3.4 \times 10^{-239}$ \\
\hline Male sex (y/n) & $1.45(1.28,1.64)$ & $2.5 \times 10^{-9}$ & $1.51(1.35,1.69)$ & $4.3 \times 10^{-13}$ & $1.64(1.44,1.87)$ & $8.6 \times 10^{-14}$ \\
\hline BMI $\left(\mathrm{kg} / \mathrm{m}^{2}\right)$ & $1.16(1.14,1.17)$ & $1.1 \times 10^{-174}$ & $1.06(1.05,1.07)$ & $3.3 \times 10^{-22}$ & $1.05(1.03,1.06)$ & $1.6 \times 10^{-11}$ \\
\hline Waist $(\mathrm{cm})$ & $1.07(1.06,1.07)$ & $9.2 \times 10^{-195}$ & $1.03(1.03,1.04)$ & $1.4 \times 10^{-52}$ & $1.03(1.03,1.04)$ & $4.4 \times 10^{-37}$ \\
\hline Glucose $(\mathrm{mmol} / \mathrm{l})$ & $12.5(11.3,13.9)$ & $<1.0 \times 10^{-350}$ & $1.82(1.64,2.02)$ & $8.2 \times 10^{-30}$ & $2.20(1.95,2.47)$ & $1.6 \times 10^{-39}$ \\
\hline $\mathrm{HbA}_{1 \mathrm{c}}(\mathrm{mmol} / \mathrm{mol})$ & $1.45(1.43,1.48)$ & $<1.0 \times 10^{-350}$ & $1.15(1.13,1.17)$ & $1.5 \times 10^{-60}$ & $1.17(1.15,1.19)$ & $6.6 \times 10^{-57}$ \\
\hline SBP $(\mathrm{mmHg})$ & $1.03(1.03,1.04)$ & $6.3 \times 10^{-74}$ & $1.03(1.03,1.03)$ & $6.9 \times 10^{-73}$ & $1.03(1.03,1.04)$ & $1.1 \times 10^{-71}$ \\
\hline DBP (mmHg) & $1.04(1.04,1.05)$ & $2.7 \times 10^{-43}$ & $1.04(1.03,1.04)$ & $1.3 \times 10^{-41}$ & $1.03(1.03,1.04)$ & $1.4 \times 10^{-23}$ \\
\hline Heart rate (bpm) & $1.01(1.01,1.02)$ & $7.1 \times 10^{-5}$ & $1.00(1.00,1.01)$ & 0.944 & $1.00(0.99,1.00)$ & 0.883 \\
\hline Cholesterol $(\mathrm{mmol} / \mathrm{l})$ & $1.20(1.14,1.28)$ & $5.7 \times 10^{-10}$ & $1.40(1.33,1.48)$ & $5.9 \times 10^{-37}$ & $1.33(1.25,1.41)$ & $2.9 \times 10^{-19}$ \\
\hline Triacylglycerol (mmol/l) & $1.44(1.39,1.50)$ & $1.1 \times 10^{-72}$ & $1.20(1.15,1.26)$ & $1.4 \times 10^{-17}$ & $1.18(1.12,1.24)$ & $1.9 \times 10^{-10}$ \\
\hline eGFR (ml/min) & $0.98(0.98,0.98)$ & $1.5 \times 10^{-24}$ & $0.97(0.96,0.97)$ & $1.2 \times 10^{-69}$ & $0.96(0.95,0.96)$ & $6.8 \times 10^{-91}$ \\
\hline Former smoker $(\mathrm{y} / \mathrm{n})$ & $1.44(1.27,1.63)$ & $1.1 \times 10^{-8}$ & $1.52(1.36,1.70)$ & $6.6 \times 10^{-13}$ & $1.53(1.34,1.75)$ & $3.9 \times 10^{-10}$ \\
\hline Current smoker (y/n) & $1.11(0.96,1.28)$ & 0.172 & $1.34(1.18,1.52)$ & $7.0 \times 10^{-6}$ & $1.45(1.25,1.67)$ & $8.4 \times 10^{-7}$ \\
\hline Coffee (cups/day) & $1.08(1.06,1.11)$ & $1.8 \times 10^{-9}$ & $1.09(1.07,1.12)$ & $7.6 \times 10^{-13}$ & $1.10(1.07,1.13)$ & $1.0 \times 10^{-10}$ \\
\hline Metabolic syndrome (y/n) & $8.9(7.9,10.1)$ & $6.6 \times 10^{-262}$ & $2.14(1.88,2.43)$ & $1.4 \times 10^{-30}$ & $2.24(1.93,2.60)$ & $3.8 \times 10^{-26}$ \\
\hline \multicolumn{7}{|l|}{ Multivariate model $1^{\mathrm{a}}$} \\
\hline SAF (AU) & $1.64(1.42,1.90)$ & $3.1 \times 10^{-11}$ & $1.62(1.41,1.84)$ & $1.5 \times 10^{-12}$ & $2.37(2.06,2.73)$ & $1.7 \times 10^{-33}$ \\
\hline Age (years) & $1.04(1.04,1.05)$ & $3.5 \times 10^{-44}$ & $1.06(1.05,1.06)$ & $1.2 \times 10^{-102}$ & $1.08(1.07,1.08)$ & $2.4 \times 10^{-127}$ \\
\hline \multicolumn{7}{|l|}{ Multivariate model $2^{\mathrm{b}}$} \\
\hline SAF (AU) & $1.43(1.22,1.66)$ & $4.0 \times 10^{-6}$ & $1.58(1.38,1.80)$ & $3.1 \times 10^{-11}$ & $2.32(2.01,2.67)$ & $8.8 \times 10^{-31}$ \\
\hline Age (years) & $1.03(1.03,1.04)$ & $3.5 \times 10^{-26}$ & $1.06(1.05,1.06)$ & $4.2 \times 10^{-96}$ & $1.08(1.07,1.08)$ & $3.1 \times 10^{-122}$ \\
\hline Metabolic syndrome (y/n) & $7.3(6.4,8.3)$ & $4.3 \times 10^{-208}$ & $1.54(1.35,1.76)$ & $1.6 \times 10^{-10}$ & $1.44(1.23,1.68)$ & $4.0 \times 10^{-6}$ \\
\hline \multicolumn{7}{|l|}{ Multivariate model $3 \mathrm{a}^{\mathrm{c}}$} \\
\hline SAF (AU) & $1.40(1.20,1.65)$ & $3.0 \times 10^{-5}$ & $1.60(1.40,1.83)$ & $6.0 \times 10^{-12}$ & $2.34(2.03,2.70)$ & $1.9 \times 10^{-31}$ \\
\hline Age (years) & $1.02(1.01,1.02)$ & $1.0 \times 10^{-6}$ & $1.06(1.05,1.06)$ & $2.4 \times 10^{-93}$ & $1.08(1.07,1.08)$ & $9.8 \times 10^{-116}$ \\
\hline Glucose $(\mathrm{mmol} / \mathrm{l})$ & $11.2(10.0,12.5)$ & $<1.0 \times 10^{-350}$ & $1.20(1.08,1.34)$ & 0.001 & $1.29(1.14,1.46)$ & $7.2 \times 10^{-5}$ \\
\hline \multicolumn{7}{|l|}{ Multivariate model $3 b^{c}$} \\
\hline SAF (AU) & $1.41(1.21,1.65)$ & $8.0 \times 10^{-6}$ & $1.58(1.38,1.81)$ & $2.1 \times 10^{-11}$ & $2.37(2.06,2.73)$ & $1.4 \times 10^{-32}$ \\
\hline Age (years) & $1.01(1.00,1.01)$ & 0.058 & $1.06(1.05,1.06)$ & $1.5 \times 10^{-79}$ & $1.08(1.07,1.08)$ & $3.5 \times 10^{-107}$ \\
\hline $\mathrm{HbA}_{1 \mathrm{c}}(\mathrm{mmol} / \mathrm{mol})$ & $1.43(1.40,1.46)$ & $1.0 \times 10^{-265}$ & $1.05(1.03,1.06)$ & $2.0 \times 10^{-6}$ & $1.02(1.00,1.04)$ & 0.035 \\
\hline \multicolumn{7}{|l|}{ Multivariate model $4^{\mathrm{d}}$} \\
\hline SAF (AU) & $1.32(1.12,1.54)$ & 0.001 & $1.35(1.18,1.56)$ & $2.1 \times 10^{-5}$ & $1.98(1.71,2.30)$ & $1.0 \times 10^{-19}$ \\
\hline Age (years) & $1.04(1.03,1.04)$ & $1.1 \times 10^{-33}$ & $1.06(1.06,1.07)$ & $1.5 \times 10^{-103}$ & $1.08(1.08,1.09)$ & $3.6 \times 10^{-134}$ \\
\hline Male sex (y/n) & $0.91(0.80,1.04)$ & 0.155 & $1.21(1.07,1.36)$ & 0.002 & $1.32(1.14,1.52)$ & $1.2 \times 10^{-4}$ \\
\hline Waist (cm) & $1.06(1.06,1.07)$ & $1.4 \times 10^{-153}$ & $1.02(1.02,1.02)$ & $1.0 \times 10^{-14}$ & $1.01(1.01,1.02)$ & $7.3 \times 10^{-5}$ \\
\hline Current smoker $(\mathrm{y} / \mathrm{n})$ & $1.28(1.10,1.49)$ & 0.002 & $1.70(1.48,1.94)$ & $1.8 \times 10^{-14}$ & $1.96(1.68,2.30)$ & $5.0 \times 10^{-17}$ \\
\hline \multicolumn{7}{|l|}{ Multivariate model $5^{\mathrm{e}}$} \\
\hline SAF (AU) & $1.26(1.06,1.48)$ & 0.008 & $1.33(1.16,1.54)$ & $6.0 \times 10^{-5}$ & $1.96(1.69,2.28)$ & $6.7 \times 10^{-19}$ \\
\hline Age (years) & $1.02(1.02,1.03)$ & $3.8 \times 10^{-8}$ & $1.06(1.05,1.06)$ & $3.4 \times 10^{-58}$ & $1.08(1.08,1.09)$ & $9.1 \times 10^{-84}$ \\
\hline Male sex (y/n) & $0.65(0.57,0.75)$ & $6.4 \times 10^{-10}$ & $1.16(1.03,1.31)$ & 0.019 & $1.25(1.08,1.44)$ & 0.003 \\
\hline Waist (cm) & $1.03(1.02,1.04)$ & $1.2 \times 10^{-26}$ & $1.02(1.01,1.02)$ & $2.4 \times 10^{-9}$ & $1.01(1.00,1.02)$ & 0.009 \\
\hline Glucose $(\mathrm{mmol} / \mathrm{l})$ & $8.9(8.0,10.0)$ & $2.0 \times 10^{-302}$ & $0.96(0.85,1.08)$ & 0.458 & $1.10(0.96,1.26)$ & 0.172 \\
\hline SBP (mmHg) & $1.00(1.00,1.01)$ & 0.175 & $1.01(1.01,1.01)$ & $2.7 \times 10^{-7}$ & $1.01(1.00,1.01)$ & $4.5 \times 10^{-4}$ \\
\hline
\end{tabular}


Table 4 (continued)

\begin{tabular}{|c|c|c|c|c|c|c|}
\hline \multirow[t]{2}{*}{ Analysis } & \multicolumn{2}{|l|}{ New T2DM } & \multicolumn{2}{|l|}{ New CVD } & \multicolumn{2}{|l|}{ Death } \\
\hline & OR $(95 \% \mathrm{CI})$ & $p$ value & OR $(95 \% \mathrm{CI})$ & $p$ value & OR $(95 \% \mathrm{CI})$ & $p$ value \\
\hline Cholesterol (mmol/l) & $0.84(0.78,0.90)$ & $9.4 \times 10^{-7}$ & $1.05(0.99,1.11)$ & 0.149 & $0.91(0.85,0.98)$ & 0.014 \\
\hline Triacylglycerol (mmol/l) & $1.24(1.18,1.30)$ & $9.9 \times 10^{-19}$ & $1.06(0.99,1.13)$ & 0.088 & $1.05(0.96,1.14)$ & 0.275 \\
\hline eGFR (ml/min) & $1.00(1.00,1.01)$ & 0.120 & $1.00(0.99,1.00)$ & 0.706 & $1.00(1.00,1.01)$ & 0.641 \\
\hline Current smoker (y/n) & $1.22(1.04,1.44)$ & 0.017 & $1.69(1.47,1.94)$ & $7.7 \times 10^{-14}$ & $1.96(1.67,2.30)$ & $1.5 \times 10^{-16}$ \\
\hline
\end{tabular}

${ }^{\text {a Age-corrected }}$

${ }^{\mathrm{b}}$ Including the metabolic syndrome

${ }^{\mathrm{c}}$ Including glycaemic measures

${ }^{\mathrm{d}}$ Without biochemical markers

${ }^{\mathrm{e}}$ With all variables

DBP, diastolic BP; SBP, systolic BP; T2DM, type 2 diabetes; $y / n$, yes/no

SAF and macro- and microvascular complications of type 2 diabetes, prospective studies regarding the predictive value of SAF are scarce and limited to selected patient populations $[19$,

Table 5 Predictive value of age-corrected SAF score for the composite outcome and the three individual outcomes according to participants' baseline age

\begin{tabular}{|c|c|c|c|c|}
\hline Outcome & $n$ & $n(\%)$ events & OR SAF $z$ score & $p$ value \\
\hline \multicolumn{5}{|l|}{ Composite } \\
\hline \multicolumn{5}{|c|}{ Age (years) } \\
\hline$\leq 35$ & 17,412 & $144(0.8)$ & $1.86(1.13,3.06)$ & 0.014 \\
\hline $36-50$ & 36,963 & $1272(3.4)$ & $2.02(1.76,2.32)$ & $2.1 \times 10^{-23}$ \\
\hline $51-60$ & 10,605 & $651(6.1)$ & $1.70(1.40,2.06)$ & $6.8 \times 10^{-8}$ \\
\hline$\geq 61$ & 7900 & $1064(13.5)$ & $1.84(1.60,2.12)$ & $2.1 \times 10^{-17}$ \\
\hline \multicolumn{5}{|c|}{ Type 2 diabetes } \\
\hline \multicolumn{5}{|c|}{ Age (years) } \\
\hline$\leq 35$ & 17,412 & $66(0.4)$ & $1.53(0.71,3.29)$ & 0.277 \\
\hline $36-50$ & 36,963 & $489(1.3)$ & $2.03(1.64,2.52)$ & $8.8 \times 10^{-11}$ \\
\hline $51-60$ & 10,605 & $230(2.2)$ & $1.28(0.92,1.79)$ & 0.140 \\
\hline$\geq 61$ & 7900 & $271(3.4)$ & $1.39(1.07,1.80)$ & 0.014 \\
\hline \multicolumn{5}{|l|}{ CVD } \\
\hline \multicolumn{5}{|c|}{ Age (years) } \\
\hline$\leq 35$ & 17,412 & $53(0.3)$ & $1.56(0.66,3.71)$ & 0.310 \\
\hline $36-50$ & 36,963 & $502(1.4)$ & $1.52(1.21,1.92)$ & $3.1 \times 10^{-4}$ \\
\hline $51-60$ & 10,605 & $284(2.7)$ & $1.62(1.22,2.15)$ & 0.001 \\
\hline$\geq 61$ & 7900 & $419(5.3)$ & $1.68(1.37,2.06)$ & $7.8 \times 10^{-7}$ \\
\hline \multicolumn{5}{|l|}{ Mortality } \\
\hline \multicolumn{5}{|c|}{ Age (years) } \\
\hline$\leq 35$ & 17,412 & $25(0.1)$ & $3.45(1.41,8.44)$ & 0.007 \\
\hline $36-50$ & 36,963 & $306(0.8)$ & $2.78(2.18,3.54)$ & $1.8 \times 10^{-16}$ \\
\hline $51-60$ & 10,605 & $164(1.6)$ & $2.47(1.75,3.49)$ & $3.0 \times 10^{-7}$ \\
\hline$\geq 61$ & 7900 & $433(5.5)$ & $2.13(1.75,2.60)$ & $7.7 \times 10^{-14}$ \\
\hline
\end{tabular}

ORs are shown with $95 \%$ CIs
23, 24]. SAF has been shown to be a prognostic factor for cardiac mortality in individuals with diabetes [45] and in those receiving haemodialysis [46-48]. De Vos et al have shown that SAF predicts all-cause mortality and major adverse cardiovascular events in participants with peripheral artery disease after 5 years of follow-up [25]. Moreover, in the same patient population, they found that SAF predicted lower limb amputation independently of diabetes status and disease severity after 6 years of follow-up [26]. Addition of SAF to the Fontaine classification, a method to assess severity of peripheral artery disease, improved the prediction of amputation significantly.

Both previous and present findings support the clinical utility of SAF as a first screening method for type 2 diabetes, CVD and mortality. Other risk indicators, such as presence of the metabolic syndrome, require more extensive measurements, including a fasting blood sample to measure glucose, HDL-cholesterol and triacylglycerol, but $\mathrm{HbA}_{1 \mathrm{c}}$ solves the need for measuring fasting glucose. The quick, non-invasive measurement of SAF may even allow use in non-medical settings or public locations such as supermarkets, pharmacies or drug stores as a first estimate of risk. The AGE reader in the present study may be used to calculate SAF percentiles using measurements in healthy participants, based on the data from Koetsier et al [20]. The present version of the device can account for both age and sex, but BMI and smoking status might also be accounted for, to produce a more balanced interpretation of the SAF value.

Strengths and limitations We have presented data from a prospective population-based study that included almost 73,000 participants within a broad range of age and cardiovascular risk. This is the first prospective study to examine SAF as a predictor for type 2 diabetes, CVD and mortality in the general population. Although Lifelines extensively collected information on medication use at baseline, unfortunately no data were 
available on the use of new medications or changes in medications, as this information was not included in the follow-up questionnaires. Medication use, in particular oral bloodglucose-lowering agents and/or insulin, can validate selfreported diagnosis of type 2 diabetes, or even ascertain the presence of diabetes when a participant does not report diabetes correctly in the questionnaire. Also, data regarding the exact time of diabetes diagnosis and CVD events were not collected. As a consequence, we were not able to perform survival analyses for both diseases. We do not have followup blood glucose or $\mathrm{HbA}_{1 \mathrm{c}}$ measurements for 16,720 participants. This may underestimate the incidence of type 2 diabetes, and could alter the effects described.

As the study has been performed in people of Western European descent, the results may not be generalisable to other populations.

Finally, future studies need to incorporate the specific cause of death in order to further refine the predictive power of SAF.

Conclusions This is the first prospective study in the general population to show the predictive value of SAF for incident type 2 diabetes, CVD and mortality. SAF significantly predicted the risk of these outcomes independently of several conventional risk factors. A longer follow-up of Lifelines participants will allow further validation and will expand the present findings.

Acknowledgements The authors acknowledge the services of the Lifelines Cohort Study, the contributing research centres delivering data to Lifelines, and all the study participants.

Data availability The manuscript is based on data from the Lifelines Cohort Study. Lifelines adheres to standards for data availability. The data catalogue of Lifelines is publicly accessible at www.lifelines.nl. All international researchers can obtain data at the Lifelines research office (research@lifelines.nl), for which a fee is required. The Lifelines system allows access for reproducibility of the study results.

Funding Lifelines has been funded by a number of public sources, notably the Dutch Government, the Netherlands Organization of Scientific Research (NWO) (grant 175.010.2007.006), FES (Fonds Economische Structuurversterking), SNN (Samenwerkingsverband Noord Nederland) and REP (Ruimtelijk Economisch Programma), Dutch Ministry of Economic Affairs, Pieken in de Delta, Provinces of Groningen and Drenthe, the Target project, BBMRI-NL (Biobanking and BioMolecular resources Research Infrastructure-the Netherlands), the University of Groningen and the University Medical Center Groningen, the Netherlands. This work was supported by the National Consortium for Healthy Ageing and funds from the European Union's Seventh Framework programme (FP7/2007-2013) through the BioSHaRE-EU (Biobank Standardisation and Harmonisation for Research Excellence in the European Union) project, grant agreement 261433.

Duality of interest RG and AJS are founders and shareholders in Diagnoptics Technologies (Groningen, the Netherlands), manufacturer of the AGE reader that was used in the present study. All other authors declare that there is no duality of interest associated with this manuscript.

Contribution statement RPvW, SNS, MMvdK and BHRW contributed to the study design. RPvW, SNS and BHRW performed the statistical analyses. All authors contributed to the analyses and interpretation of the data. RPvW drafted the initial version of the manuscript. All authors participated in the critical revision of the manuscript and approved the final version. BHRW is the guarantor of this work.

Open Access This article is distributed under the terms of the Creative Commons Attribution 4.0 International License (http:// creativecommons.org/licenses/by/4.0/), which permits unrestricted use, distribution, and reproduction in any medium, provided you give appropriate credit to the original author(s) and the source, provide a link to the Creative Commons license, and indicate if changes were made.

\section{References}

1. Wolffenbuttel BHR, Van Haeften TW (1995) Prevention of complications in non-insulin-dependent diabetes mellitus (NIDDM). Drugs 50(2):263-288. https://doi.org/10.2165/00003495199550020-00006

2. Brownlee $\mathrm{M}(2005)$ The pathobiology of diabetic complications: a unifying mechanism. Diabetes 54(6):1615-1625. https://doi.org/ 10.2337/diabetes.54.6.1615

3. Ford ES (2011) Trends in the risk for coronary heart disease among adults with diagnosed diabetes in the U.S.: findings from the National Health and Nutrition Examination Survey, 1999-2008. Diabetes Care 34(6):1337-1343. https://doi.org/10.2337/dc10-2251

4. Lindstrom J, Tuomilehto J (2003) The diabetes risk score: a practical tool to predict type 2 diabetes risk. Diabetes Care 26(3):725731. https://doi.org/10.2337/diacare.26.3.725

5. Conroy RM, Pyorala K, Fitzgerald AP et al (2003) Estimation of ten-year risk of fatal cardiovascular disease in Europe: the SCORE project. Eur Heart J 24(11):987-1003. https://doi.org/10.1016/ S0195-668X(03)00114-3

6. D'Agostino RB Sr, Vasan RS, Pencina MJ et al (2008) General cardiovascular risk profile for use in primary care: the Framingham Heart Study. Circulation 117(6):743-753. https://doi. org/10.1161/CIRCULATIONAHA.107.699579

7. Noble D, Mathur R, Dent T, Meads C, Greenhalgh T (2011) Risk models and scores for type 2 diabetes: systematic review. BMJ 343 : d7163. https://doi.org/10.1136/bmj.d7163

8. Monnier VM (1990) Nonenzymatic glycosylation, the Maillard reaction and the aging process. J Gerontol 45(4):B105-B111. https:// doi.org/10.1093/geronj/45.4.B105

9. Brownlee M (1995) Advanced protein glycosylation in diabetes and aging. Annu Rev Med 46(1):223-234. https://doi.org/10. 1146/annurev.med.46.1.223

10. Baynes JW, Thorpe SR (2000) Glycoxidation and lipoxidation in atherogenesis. Free Radic Biol Med 28(12):1708-1716. https://doi. org/10.1016/S0891-5849(00)00228-8

11. Aronson D (2003) Cross-linking of glycated collagen in the pathogenesis of arterial and myocardial stiffening of aging and diabetes. $\mathrm{J}$ Hypertens 21(1):3-12. https://doi.org/10.1097/00004872200301000-00002

12. Liu CY, Huang QF, Cheng YB et al (2017) A comparative study on skin and plasma advanced glycation end products and their associations with arterial stiffness. Pulse (Basel) 4(4):208-218. https:// doi.org/10.1159/000453581

13. Basta G, Schmidt AM, De Caterina R (2004) Advanced glycation end products and vascular inflammation: implications for accelerated atherosclerosis in diabetes. Cardiovasc Res 63(4):582-592. https://doi.org/10.1016/j.cardiores.2004.05.001

14. Isermann B, Bierhaus A, Humpert PM et al (2004) AGE-RAGE: a hypothesis or a mechanism? Herz 29(5):504-509 [article in German]. https://doi.org/10.1007/s00059-004-2611-3 
15. Lin N, Zhang H, Su Q (2012) Advanced glycation end-products induce injury to pancreatic beta cells through oxidative stress. Diabetes Metab 38(3):250-257. https://doi.org/10.1016/j.diabet.2012.01.003

16. Vlassara H, Uribarri J (2014) Advanced glycation end products (AGE) and diabetes: cause, effect, or both? Curr Diab Rep 14(1): 453. https://doi.org/10.1007/s11892-013-0453-1

17. Meerwaldt R, Graaff R, Oomen PHN et al (2004) Simple noninvasive assessment of advanced glycation endproduct accumulation. Diabetologia 47(7):1324-1330. https://doi.org/10.1007/ s00125-004-1451-2

18. Meerwaldt R, Links T, Graaff R et al (2005) Simple noninvasive measurement of skin autofluorescence. Ann N Y Acad Sci 1043(1): 290-298. https://doi.org/10.1196/annals.1333.036

19. Lutgers HL, Graaff R, Links TP et al (2006) Skin autofluorescence as a noninvasive marker of vascular damage in patients with type 2 diabetes. Diabetes Care 29(12):2654-2659. https://doi.org/10. 2337/dc05-2173

20. Koetsier M, Lutgers HL, de Jonge C, Links TP, Smit AJ, Graaff R (2010) Reference values of skin autofluorescence. Diabetes Technol Ther 12(5):399-403. https://doi.org/10.1089/dia.2009.0113

21. Van Waateringe RP, Slagter SN, van Beek AP et al (2017) Skin autofluorescence, a non-invasive biomarker for advanced glycation end products, is associated with the metabolic syndrome and its individual components. Diabetol Metab Syndr 9(1):42. https://doi. org/10.1186/s13098-017-0241-1

22. Gerrits EG, Lutgers HL, Kleefstra N et al (2008) Skin autofluorescence: a tool to identify type 2 diabetic patients at risk for developing microvascular complications. Diabetes Care 31(3):517-521. https://doi.org/10.2337/dc07-1755

23. Noordzij MJ, Mulder DJ, Oomen PH et al (2012) Skin autofluorescence and risk of micro- and macrovascular complications in patients with type 2 diabetes mellitus-a multi-centre study. Diabet Med 29(12):1556-1561. https://doi.org/10.1111/dme.12005

24. Tanaka K, Tani Y, Asai J et al (2012) Skin autofluorescence is associated with severity of vascular complications in Japanese patients with type 2 diabetes. Diabet Med 29(4):492-500. https://doi. org/10.1111/j.1464-5491.2011.03448.x

25. De Vos LC, Mulder DJ, Smit AJ et al (2014) Skin autofluorescence is associated with 5-year mortality and cardiovascular events in patients with peripheral artery disease. Arterioscler Thromb Vasc Biol 34(4): 933-938. https://doi.org/10.1161/ATVBAHA.113.302731

26. De Vos LC, Boersema J, Mulder DJ, Smit AJ, Zeebregts CJ, Lefrandt JD (2015) Skin autofluorescence as a measure of advanced glycation end products deposition predicts 5-year amputation in patients with peripheral artery disease. Arterioscler Thromb Vasc Biol 35(6):15321537. https://doi.org/10.1161/ATVBAHA.115.305407

27. Stolk RP, Rosmalen JG, Postma DS et al (2008) Universal risk factors for multifactorial diseases: LifeLines: a three-generation population-based study. Eur J Epidemiol 23(1):67-74. https://doi. org/10.1007/s10654-007-9204-4

28. Scholtens S, Smidt N, Swertz MA et al (2015) Cohort profile: LifeLines, a three-generation cohort study and biobank. Int J Epidemiol 44(4):1172-1180. https://doi.org/10.1093/ije/dyu229

29. Van Waateringe RP, Slagter SN, van der Klauw MM et al (2016) Lifestyle and clinical determinants of skin autofluorescence in a population-based cohort study. Eur J Clin Investig 46(5):481-490. https://doi.org/10.1111/eci.12627

30. Koetsier M, Nur E, Chunmao H et al (2010) Skin color independent assessment of aging using skin autofluorescence. Opt Express 18(14):14416-14429. https://doi.org/10.1364/OE.18.014416

31. Levey AS, Stevens LA, Schmid CH et al (2009) A new equation to estimate glomerular filtration rate. Ann Intern Med 150(9):604612. https://doi.org/10.7326/0003-4819-150-9-200905050-00006

32. Alberti KG, Eckel RH, Grundy SM et al (2009) Harmonizing the metabolic syndrome: a joint interim statement of the International Diabetes Federation Task Force on Epidemiology and Prevention;
National Heart, Lung, and Blood Institute; American Heart Association; World Heart Federation; International Atherosclerosis Society; and International Association for the Study of Obesity. Circulation 120(16):1640-1645. https://doi.org/ 10.1161/CIRCULATIONAHA.109.192644

33. Dyer DG, Dunn JA, Thorpe SR et al (1993) Accumulation of Maillard reaction products in skin collagen in diabetes and aging. J Clin Invest 91(6):2463-2469. https://doi.org/10.1172/JCI116481

34. Maynard JD, Rohrscheib M, Way JF, Nguyen CM, Ediger MN (2007) Noninvasive type 2 diabetes screening: superior sensitivity to fasting plasma glucose and A1C. Diabetes Care 30(5):1120 1124. https://doi.org/10.2337/dc06-2377

35. Smit AJ, Smit JM, Botterblom GJ, Mulder DJ (2013) Skin autofluorescence based decision tree in detection of impaired glucose tolerance and diabetes. PLoS One 8(6):e65592. https://doi.org/10. 1371/journal.pone.0065592

36. Fokkens BT, van Waateringe RP, Mulder DJ, Wolffenbuttel BHR, Smit AJ (2018) Skin autofluorescence improves the Finnish Diabetes Risk Score in the detection of diabetes in a large population-based cohort: the LifeLines Cohort Study. Diabetes Metab 44(5):424-430. https://doi.org/10.1016/j.diabet.2017.09.002

37. Kuk JL, Ardern CI (2010) Age and sex differences in the clustering of metabolic syndrome factors: association with mortality risk. Diabetes Care 33(11):2457-2461. https://doi.org/10.2337/dc10-0942

38. Klein BE, Klein R, Lee KE (2002) Components of the metabolic syndrome and risk of cardiovascular disease and diabetes in Beaver Dam. Diabetes Care 25(10):1790-1794. https://doi.org/10.2337/ diacare.25.10.1790

39. Mons U, Muezzinler A, Gellert C et al (2015) Impact of smoking and smoking cessation on cardiovascular events and mortality among older adults: meta-analysis of individual participant data from prospective cohort studies of the CHANCES consortium. BMJ 350:h1551. https://doi.org/10.1136/bmj.h1551

40. Teo KK, Ounpuu S, Hawken S et al (2006) Tobacco use and risk of myocardial infarction in 52 countries in the INTERHEART study: a case-control study. Lancet 368(9536):647-658. https://doi.org/10. 1016/S0140-6736(06)69249-0

41. Cerami C, Founds H, Nicholl I et al (1997) Tobacco smoke is a source of toxic reactive glycation products. Proc Natl Acad Sci U S A 94(25):13915-13920. https://doi.org/10.1073/pnas.94.25.13915

42. Nicholl ID, Stitt AW, Moore JE, Ritchie AJ, Archer DB, Bucala R (1998) Increased levels of advanced glycation endproducts in the lenses and blood vessels of cigarette smokers. Mol Med 4(9):594 601. https://doi.org/10.1007/BF03401759

43. Yanbaeva DG, Dentener MA, Creutzberg EC, Wesseling G, Wouters EF (2007) Systemic effects of smoking. Chest 131(5): 1557-1566. https://doi.org/10.1378/chest.06-2179

44. Van Waateringe RP, Mook-Kanamori MJ, Slagter SN et al (2017) The association between various smoking behaviors, cotinine biomarkers and skin autofluorescence, a marker for advanced glycation end product accumulation. PLoS One 12(6):e0179330. https://doi.org/10.1371/journal.pone.0179330

45. Meerwaldt R, Lutgers HL, Links TP et al (2007) Skin autofluorescence is a strong predictor of cardiac mortality in diabetes. Diabetes Care 30(1):107-112. https://doi.org/10.2337/dc06-1391

46. Meerwaldt R, Hartog JW, Graaff R et al (2005) Skin autofluorescence, a measure of cumulative metabolic stress and advanced glycation end products, predicts mortality in hemodialysis patients. J Am Soc Nephrol 16(12):3687-3693. https://doi.org/10.1681/ ASN.2005020144

47. Fraser SD, Roderick PJ, McIntyre NJ et al (2014) Skin autofluorescence and all-cause mortality in stage 3 CKD. Clin J Am Soc Nephrol 9(8):1361-1368. https://doi.org/10.2215/CJN.09510913

48. Macsai E, Benke A, Kiss I (2015) Skin autofluorescence and mortality in patients on peritoneal dialysis. Medicine (Baltimore) 94(45):e1933. https://doi.org/10.1097/MD.0000000000001933 